\title{
Volume shrinkages and mechanical properties of various fiber-reinforced hydroxyethyl methacrylate-polyurethane/unsaturated polyester composites
}

\author{
S.P. Lin ${ }^{\text {a }}$, J.H. Shen ${ }^{\text {a }}$, J.L. Han ${ }^{\text {d }}$, Y.J. Lee ${ }^{\text {c }, ~ K . H . ~ L i a o ~}{ }^{\text {a }}$, J.T. Yeh ${ }^{\text {e }}$, \\ F.C. Chang ${ }^{\text {f }}$, K.H. Hsieh ${ }^{\mathrm{a}, \mathrm{b}, *}$ \\ a Institute of Polymer Science and Engineering, National Taiwan University, Taipei 106, Taiwan \\ ${ }^{\mathrm{b}}$ Department of Chemical Engineering, National Taiwan University, Taipei 106, Taiwan \\ ${ }^{c}$ Department of Engineering Science and Ocean Engineering, National Taiwan University, Taipei 106, Taiwan \\ ${ }^{\mathrm{d}}$ Department of Chemical and Materials Engineering, National I-Lan University, I-Lan 260, Taiwan \\ ${ }^{\mathrm{e}}$ Department of Textile Science, Nanya Institute of Technology, Taoyuan 414, Taiwan \\ ${ }^{\mathrm{f}}$ Department of Applied Chemistry, National Chiao Tung University, Hsin-Chu 300, Taiwan
}

Received 19 March 2007; received in revised form 28 August 2007; accepted 13 September 2007

Available online 1 October 2007

\begin{abstract}
In this study, two kinds of hydroxyethyl methacrylate-polyurethane (HEMA-PU) were used as volume shrinkage modifiers, and several hydroxyethyl methacrylate-polyurethane modified unsaturated polyester (HEMA-PU/St./UP) resins crosslinked with styrene were synthesized and characterized using Fourier transform infrared (FTIR) spectroscopy, scanning electron microscopy (SEM), and in terms of their mechanical properties, including their tensile strengths and Izod impact energies. The properties of the HEMA-PU-modified St./ UP and St./UP were compared for potential applications as matrices for glass fiber-, aramid fiber-, and UHMWPE fiber-reinforced composites. The effects of the HEMA-PU content and the type of polyol in the HEMA-PU resin matrices of the composites were investigated through testing of their mechanical properties, bulletproof testing, and observations of their morphologies.
\end{abstract}

(c) 2007 Elsevier Ltd. All rights reserved.

Keywords: A. Fibres; A. Polymer-matrix composites (PMCs); B. Mechanical properties; B. Infrared (IR) spectroscopy

\section{Introduction}

Although unsaturated polyester resins are used in many industrial applications because of their good mechanical properties, high processability, and high chemical resistance, they often undergo undesirably high volume shrinkage. To reduce the volume shrinkage of the matrix system, many researchers $[1-3]$ have attempted to prepare modified polymer reins, for use as matrices in composites, from unsaturated polyester resins. Cao et al. $[4,5]$ found that the addition of low-profile additives (LPA) reduced the

\footnotetext{
* Corresponding author. Address: Institute of Polymer Science and Engineering, National Taiwan University, Taipei 106, Taiwan. Tel.: +886 23366 5314; fax: +88623366 5237 .

E-mail address: khhsieh@ntu.edu.tw (K.H. Hsieh).
}

UP resin's shrinkage, but increased the residual styrene (St.) content; they also found that the use of an unsaturated polyester at a low MMA/styrene ratio led to a lower amount of styrene residue with almost unchanged shrinkage, whereas a high MMA/styrene ratio reduced the residual styrene adequately but with poor volume shrinkage control. Li et al. [6-9] studied the low-temperature curing shrinkage control mechanism of LPA; they demonstrated that the shrinkage behavior of the resin mixture is dependent upon the competition between the shrinkage arising from polymerization and the expansion arising from microvoid formation. Huang et al. [10-12] found that the addition of LPA enhanced the degree of phase separation between LPA and a styrene-crosslinked polyester resin, such that microgel particles could be identified throughout 
the reaction; they also observed the morphologies of styrene-crosslinked polyester containing various LPA content. Zhang et al. [13] described how compatible LPAs yielded more-homogeneous matrices than did immiscible ones.

Fiber-reinforced polymer composites are used widely in material applications. Several kinds of fibers have been applied as reinforcing materials, including carbon fibers $[14,15]$, glass fibers [16-19], aramid fibers, and ultrahighmolecular-weight polyethylene (UHMWPE) fibers [20,21].

In this study, we synthesized eight sets of HEMA-PU/ St./UP resin systems possessing various HEMA-PU contents and polyol types to investigate their volume shrinkages and mechanical properties, including their tensile strengths and Izod impact energies, and compared them with those of traditional UP resins. For the manufacture of the fiber-reinforced composites, we incorporated four types of fiber reinforcement material (i.e., E- and P-type glass fibers, aramid fiber, and UHMWPE fiber) into two different HEMA-PU/St./UP matrices and then determined the bulletproof nature and mechanical properties of the systems, including their tensile strengths and elongations.
We obtained SEM images to observe the fracture behavior and wet-out properties of these composites. The bulletproof properties of the UHMWPE fiber reinforced HEMA-PU/St./UP and aramid fiber reinforced HEMAPU/St./UP composites of different thickness were also investigated in this study $[22,23]$.

\section{Experimental}

The materials used are listed in Table 1. Two polyols, PBA 700 and PPG 400, were heated and degassed under vacuum overnight prior to use.

\subsection{Preparation of Polyurethane prepolymer and HEMA-PU}

The preparation of $\mathrm{PU}$ prepolymer was mentioned elsewhere before $[23,24]$. The HEMA-PU polymer was prepared by reacting HEMA (2 equiv.) with PU prepolymer (1 equiv. based on PPG 400 or PBA 700). The molecular structures of the HEMA-PU polymers (based on PPG 400 or PBA 700) are presented below.
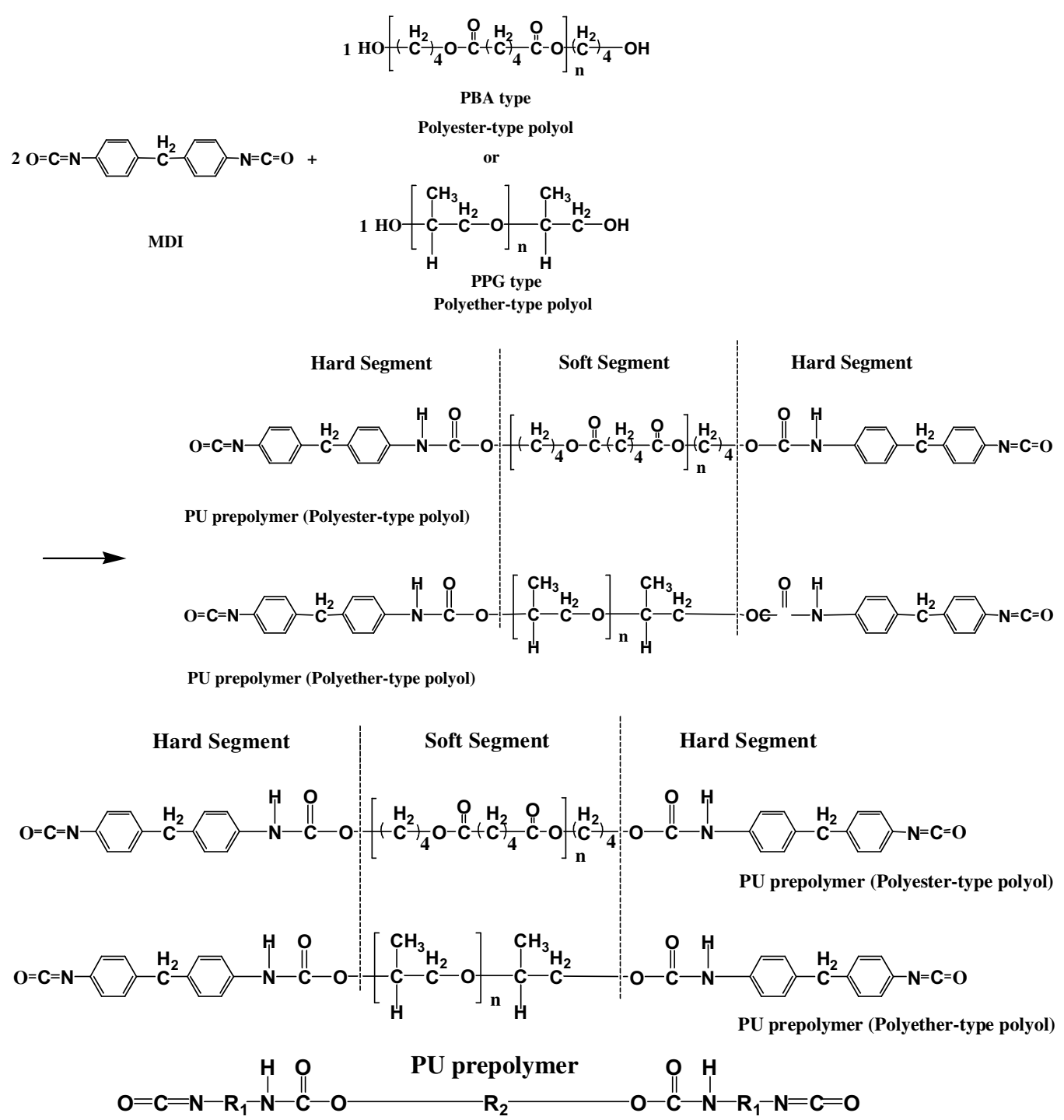


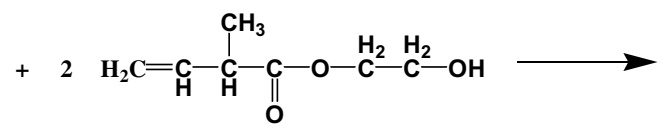

curing the HEMA-PU/St./UP (or St./UP Reins)

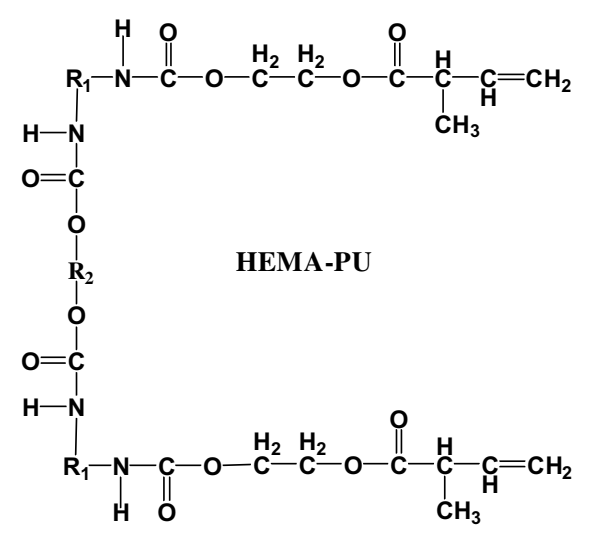

tion. Morphological studies were performed using a Tescan $5136 \mathrm{MM}$ scanning electron microscope (SEM). The tensile strengths and Izod impact energies of the various HEMAPU/St./UP and St./UP samples were measured according to the ASTM-638 and ASTM-256 protocols. The stressstrain properties of the various UHMWPE fiber-reinforced composites were measured according to the ASTM-D3039 protocol. The method of bulletproof testing was performed under National Institute of Justice ballistic standards (NIJ 0108.01 IIA and NIJ 0108.01 IIIA). The UHMWPE and aramid fibers were knitted using the Plain Weaves method of the Super Textile Corporation, Taiwan. Every 0.5-mmthick UHMWPE and aramid fiber knit was impregnated with HEMA-PU/St./UP (20/20/60, weight ratio) resin. The impregnated knits were fabricated using 6, 10, and 20 plies; and the compression method was the same as mentioned before.

\section{Results and discussion}

\subsection{FTIR spectroscopic analysis}

Fig. 1 displays the FTIR spectra of HEMA-PU(PBA 700) resin. A broad peak for the $-\mathrm{OH}$ groups

Table 1

Experimental materials

\begin{tabular}{ll}
\hline Designation & Description \\
\hline $\begin{array}{c}\text { UHMWPE } \\
\text { fiber }\end{array}$ & Spectra $^{\circledR} 900$ Denier 1200 \\
Aramid fiber & Technora@ T-200 \\
Glass fiber & $450 \mathrm{~g} / \mathrm{m}^{2}$ (E-type), $300 \mathrm{~g} / \mathrm{m}^{2}$ (P-type) (Taiwan Glass \\
& Industry Co., Taiwan) \\
PBA 700 & Poly(tetramethylene adipate)glycol; MW = 700 (Tai Gin \\
$\quad$ polyol) & Co., Taiwan) \\
PPG 400 & Poly(oxypropylene)glycol; MW = 400 (Tai Gin Co., \\
(polyol) & Taiwan) \\
MDI & 4,4'-Diphenyl methane diisocyanate (TCI Chem.) \\
St. & Styrene (Acros Organics) \\
HEMA & Hydroxyethyl methacrylate (Acros Organics) \\
UP & Unsaturated polyester (Eternal Co., Taiwan) \\
MEKPO & Methyl ethyl ketone peroxide (Eternal Co., Taiwan) \\
Acetone & 2-Propanone (Acros Organics) \\
\hline
\end{tabular}

Acetone

\subsection{Preparation of UHMWPE and aramid fiber-reinforced HEMA-PU/St./UP composites}

The preparation of UHMWPE and aramid fiber-reinforced HEMA-PU/St./UP composites was described elsewhere $[22,23]$. The MEKPO initiator (5 phr) and HEMAPU/St./UP systems with various HEMA-PU contents were chosen as the matrices in this study. Unidirectional fiber reinforced composites $\left(\left[0^{\circ}\right]_{8}\right)$ and cross-ply ones $\left(\left[0^{\circ}, 90^{\circ}\right]_{2 \mathrm{~S}}\right)$ were fabricated using eight plies of manufactured pre-pregs. For mechanical testing, the various composite specimens were cut into smaller sizes using a hydraulic power cutting machine (UHO Enterprise Corporation, Taiwan).

\subsection{Testing methods}

Infrared spectra were recorded using a BIO-RAD FTS40 FT-IR spectrophotometer operated at $4 \mathrm{~cm}^{-1}$ resolu- 


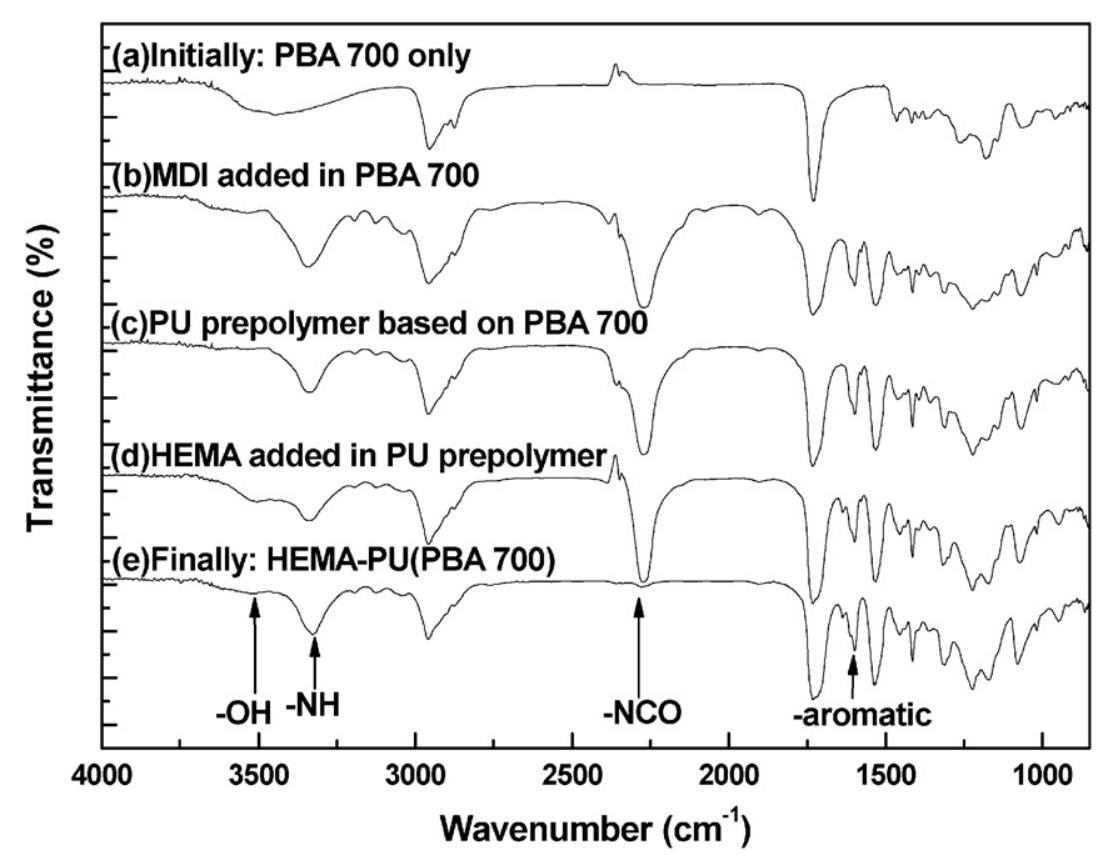

Fig. 1. FTIR spectra recorded at five different reaction stages during the synthesis of PU prepolymer based on PBA 700: (a) Initially: PBA 700 only; (b) MDI added in PBA 700; (c) PU prepolymer based on PBA 700; (d) HEMA added in PU prepolymer; (e) Finally: HEMA-PU(PBA 700).

$\left(3500 \mathrm{~cm}^{-1}\right)$ of the polyol is evident in Fig. 1a. The spectrum of the sample obtained after mixing MDI (2 equiv.) and PBA 700 ( 1 equiv.) in a purged reaction kettle is presented in Fig. 1b. During the middle stages of the reaction, the intensity of the signal of the $-\mathrm{OH}$ groups $\left(3500 \mathrm{~cm}^{-1}\right)$ gradually disappeared, while that of the signal for the $-\mathrm{NCO}$ groups $\left(2270 \mathrm{~cm}^{-1}\right)$ reduced to half of its original value (based on the signal for the $p$-phenylene moieties at $\left.840 \mathrm{~cm}^{-1}\right)$, as presented in Fig. 1c. Finally, HEMA (2 equiv.) was added to the reaction systems, as indicated in Fig. 1d. During the final stages, the peak intensity of the residual -NCO groups $\left(2270 \mathrm{~cm}^{-1}\right)$ continued to reduce until finally it remained constant, as indicated in Fig. 1e.

\subsection{Volume shrinkages and mechanical properties of various St./UP systems}

The compatibility between the styrene and the unsaturated polyester was high because they both contain benzene rings. Thus, the addition of styrene acted as a diluting modifier in the St./UP system; it diluted the viscosity of the neat unsaturated polyester resin, and enhances the mechanical properties by increasing the cross-linking density in the final St./UP networks. Table 2 lists the volume shrinkages and tensile properties of St./UP systems containing various styrene contents.

As presented in Fig. 2, the values of volume shrinkage increased linearly upon increasing the styrene contents in

Table 2

Physical properties of UP resins with different St. contents and HEMA-PU/St./UP resin systems with various HEMA-PU contents

\begin{tabular}{|c|c|c|c|c|c|}
\hline Modified UP resin systems & $\begin{array}{l}\text { PU content } \\
\left(\mathrm{wt}^{\circ} \%\right)\end{array}$ & $\begin{array}{l}\text { Styrene content } \\
(\%)\end{array}$ & $\begin{array}{l}\text { Tensile strength } \\
\text { (MPa) }\end{array}$ & $\begin{array}{l}\text { Izod impact energy } \\
(\mathrm{J} / \mathrm{m})\end{array}$ & $\begin{array}{l}\text { Volume shrinkage } \\
(\%)\end{array}$ \\
\hline Styrene/unsaturated polyester & $\begin{array}{l}0 \\
0 \\
0 \\
0 \\
0 \\
0 \\
0\end{array}$ & $\begin{array}{l}12.6 \\
19.6 \\
26.4 \\
30.5 \\
40.0 \\
44.8 \\
54.9\end{array}$ & $\begin{array}{l}13.7 \\
15.1 \\
17.3 \\
23.3 \\
25.3 \\
25.2 \\
21.3\end{array}$ & $\begin{array}{l}52.0 \\
53.5 \\
54.5 \\
57.7 \\
58.2 \\
58.3 \\
56.6\end{array}$ & $\begin{array}{r}4.1 \\
5.9 \\
6.7 \\
8.2 \\
11.3 \\
12.1 \\
13.6\end{array}$ \\
\hline $\begin{array}{l}\text { HEMA-PU(PPG)/Styrene/unsaturated } \\
\text { polyester }\end{array}$ & $\begin{array}{r}8.0 \\
10.0 \\
13.3 \\
20.0\end{array}$ & $\begin{array}{l}32.0 \\
30.0 \\
26.6 \\
20.0\end{array}$ & $\begin{array}{l}18.6 \\
17.0 \\
15.1 \\
12.9\end{array}$ & $\begin{array}{l}57.6 \\
57.9 \\
60.1 \\
60.8\end{array}$ & $\begin{array}{l}7.3 \\
7.0 \\
5.5 \\
3.5\end{array}$ \\
\hline $\begin{array}{l}\text { HEMA-PU(PBA)/Styrene/unsaturated } \\
\text { polyester }\end{array}$ & $\begin{array}{r}8.0 \\
10.0 \\
13.3 \\
20.0\end{array}$ & $\begin{array}{l}32.0 \\
30.0 \\
26.6 \\
20.0\end{array}$ & $\begin{array}{r}24.0 \\
14.1 \\
12.6 \\
5.0\end{array}$ & $\begin{array}{l}58.2 \\
58.8 \\
63.0 \\
82.3\end{array}$ & $\begin{array}{l}7.1 \\
6.9 \\
5.6 \\
2.9\end{array}$ \\
\hline
\end{tabular}




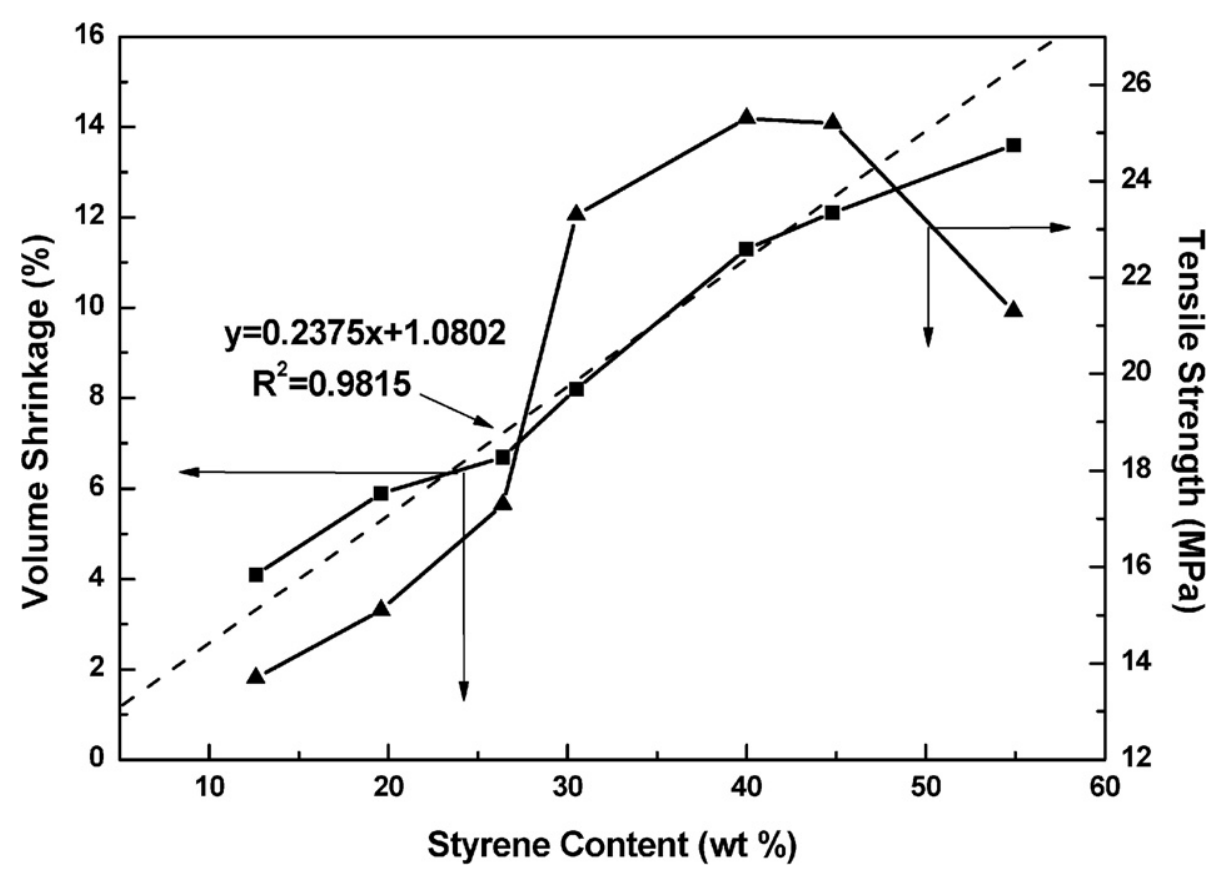

Fig. 2. Effect of the styrene content on the tensile strengths and volume shrinkages of St./UP resin systems.

the St./UP system, and the regression equation, $y=a x+b$, had values of $a$ and $b$ of 0.2375 and 1.0802 , respectively $\left(R^{2}=0.9815\right)$. Extending the regression equation to the $Y$ axis (the styrene content $=0 \%)$, the value of $b(1.0802 \%)$ represents the volume shrinkage of the neat unsaturated polyester. The positive slope value of $a$, increased upon increasing the styrene content. The tensile strength increased upon increasing the styrene content in the St./ UP system up to $40 \mathrm{wt} \%$, but then it decreased to 21.3 MPa at a styrene content of $54.9 \mathrm{wt} \%$. Thus, the optimal styrene addition for the St./UP system to provide the strongest material was $40 \mathrm{wt} \%$ (25.3 MPa). Thus, for subsequent experiments, the HEMA-PU/St./UP resin materials were prepared with the modifier (HEMA-PU/St.) content of $40 \mathrm{wt} \%$ in the unsaturated polyester resin.

\subsection{Volume shrinkages and mechanical properties of various HEMA-PUISt.IUP systems}

Table 2 lists the volume shrinkages and mechanical properties, including tensile strengths and Izod impact energies, of HEMA-PU/St./UP systems containing various HEMA-PU contents and two types of polyol (PPG 400 and PBA 700). The values of tensile strength decreased upon increasing the HEMA-PU content in the HEMA-PU(PPG 400)/St./UP and the HEMAPU(PBA 700)/St./UP systems. The HEMA-PU(PPG 400)/St./UP system exhibited higher values of tensile strength than did the HEMA-PU(PBA 700)/St./UP system when the HEMA-PU content was greater than $8 \mathrm{wt} \%$. This situation arose presumably because the HEMA-PU(PBA 700)/St./UP system contained a greater number of soft segmental structures, causing the cross- linking density in the HEMA-PU, styrene, and the unsaturated polyester network to be lower than that in the HEMA-PU(PPG 400)/St./UP system at the same HEMA-PU content.

The values of the volume shrinkage decreased upon increasing the HEMA-PU content in the HEMA-PU(PBA 700)/St./UP and the HEMA-PU(PPG 400)/St./UP systems; these two types of HEMA-PU-modified St./UP resin systems exhibited seemingly identical volume shrinkages. The lowest volume shrinkages were $3.5 \%$ for the $20 \mathrm{wt} \%$ HEMA-PU(PPG 400)- and $2.9 \%$ for the $20 \mathrm{wt} \%$ HEMA-PU(PBA 700)-modified St./UP resin system. As mentioned above in the discussion of the St./UP system, the volume shrinkage of the neat unsaturated polyester resin was $1.0802 \%$; therefore, these two polyol-containing $20 \mathrm{wt} \%$ HEMA-PU-modified St./UP resin systems possessed highly improved volume shrinkage properties. It seems that the soft segmental structures of the two polyol-modified HEMA-PU systems had been dispersed uniformly in the microvoids during the course of UP crosslinking, such that the HEMA-PU units reacted with the styrene and the unsaturated polyester resins to result in the formation of network structures during the cross-linking reaction.

In the HEMA-PU(PPG 400)/St./UP system, the Izod impact energy decreased to $57.6 \mathrm{~J} / \mathrm{m}$ at an HEMA-PU content of $8 \mathrm{wt} \%$, but increased to $60.8 \mathrm{~J} / \mathrm{m}$ at an HEMA-PU content of $20 \mathrm{wt} \%$, relative to that of the St./ UP (40/60 in weight ratio) (see Table 2). This result is consistent with the SEM images of the fracture surfaces of the HEMA-PU(PPG 400)/St./UP systems. For the $10 \mathrm{wt} \%$ HEMA-PU-containing HEMA-PU/St./UP system as shown in Fig. 3a, the fracture surface revealed many con- 
tinuous narrow shear band structures, indicating rapid crack propagation [22]. In the HEMA-PU/St./UP system containing $20 \mathrm{wt} \%$ HEMA-PU (Fig. 3b), the crack propagated from the surface across the cross-sectional area, and fracture surfaces revealed non-continuous, broader cracks. This finding suggests that the HEMA-PU(PPG 400)modified St./UP systems exhibit better load bearing charac- teristics. For the HEMA-PU(PBA 700)/St./UP system, the value of Izod impact energy increased from $58.2 \mathrm{~J} / \mathrm{m}$ at an HEMA-PU content of $8 \mathrm{wt} \%$ to $82.3 \mathrm{~J} / \mathrm{m}$ at an HEMAPU content of $20 \mathrm{wt} \%$, relative to that of the St./UP (40/60 in weight ratio) resin. This result is consistent with the SEM images in Fig. 3c and d. At higher HEMA-PU content in the HEMA-PU(PBA 700)/St./UP systems, the
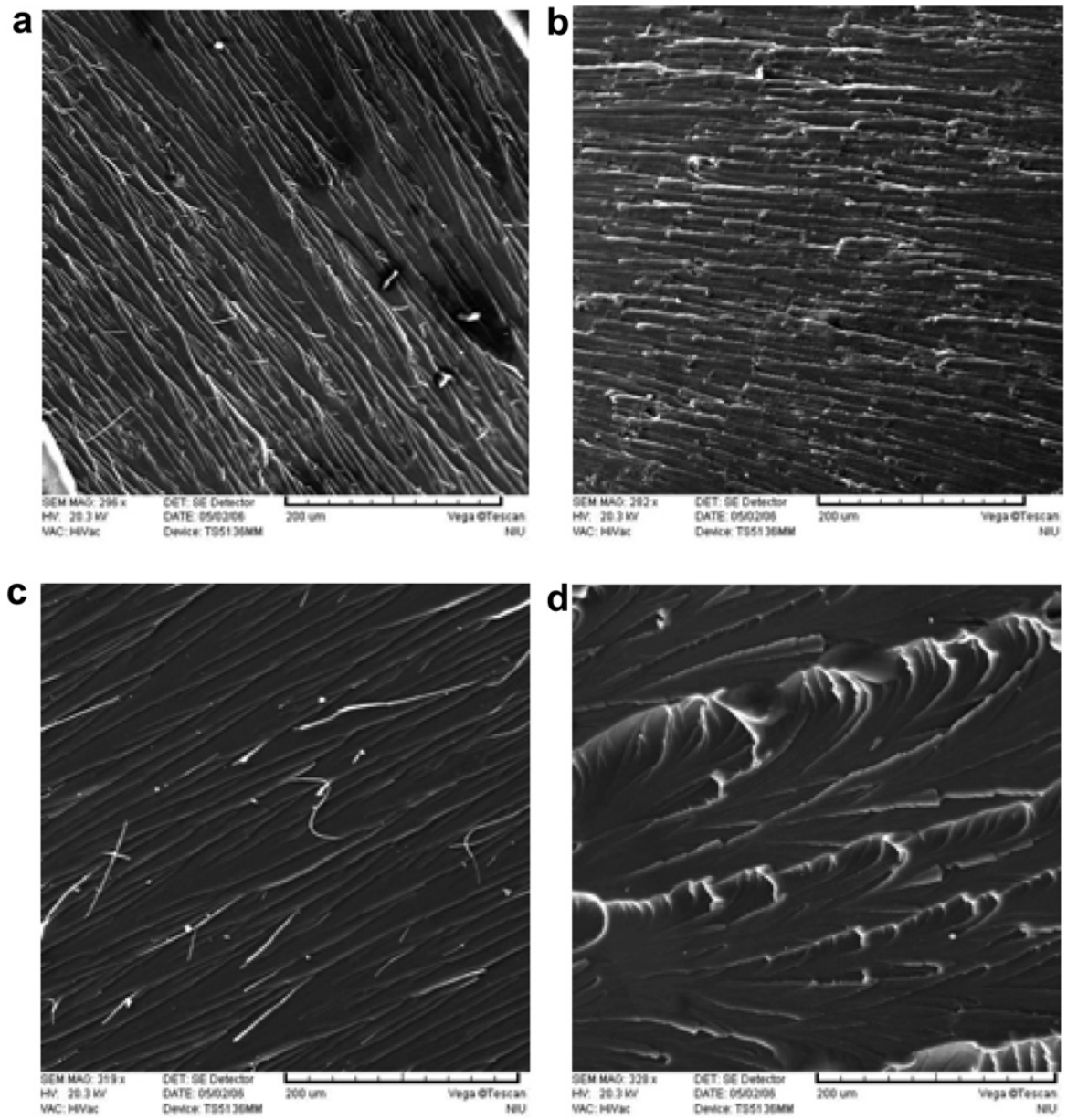

Fig. 3. SEM images of side-view fracture surfaces with various PU content in HEMA-PU/St./UP reins: (a) HEMA-PU(PPG 400) content $=10$ wt $\%$; (b) HEMA-PU(PPG 400) content $=20 \mathrm{wt} \%$; (c) HEMA-PU(PBA 700) content $=10 \mathrm{wt} \%$; (d) HEMA-PU(PBA 700$)$ content $=20 \mathrm{wt} \%$.

Table 3

Mechanical properties of various UHMWPE fiber-, Aramid fiber-, and glass fiber-reinforced HEMA-PU(PBA 700)/St./UP composites

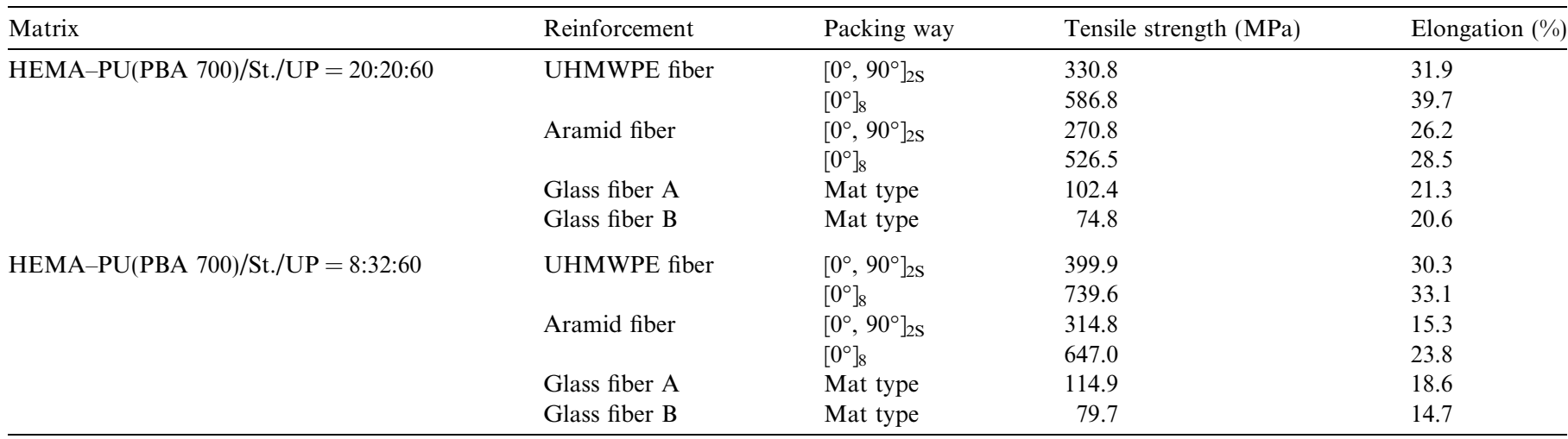


fracture paths exhibited discontinuous, convoluted, and large feather-like features; the fracture surfaces that spread from the bottom upward are presumably responsible for the higher toughness and load bearing characteristics.

Thus, a lower HEMA-PU content $(8 \mathrm{wt} \%)$ in the HEMA-PU/St./UP resin system led to a higher tensile strength, whereas a high HEMA-PU content $(20 \mathrm{wt} \%)$ improved the Izod impact energy and led to a smaller volume shrinkage for both types of polyol-containing HEMA-PU/St./UP systems. The HEMA-PU(PBA 700)/ St./UP systems exhibited superior values for their tensile and Izod impact energies relative to those of the HEMAPU(PPG 400)/St./UP systems at both 8 and $20 \mathrm{wt} \%$
HEMA-PU content. Thus, for manufacturing subsequent fiber-reinforced composite materials, we incorporated 8 and $20 \mathrm{wt} \%$ of HEMA-PU into the HEMA-PU(PBA 700)/St./UP systems.

\subsection{Mechanical properties of various fiber-reinforced composites}

Table 3 lists the mechanical properties, including tensile strength, elongation, and Izod impact energy, of various glass fiber-, aramid fiber-, and UHMWPE fiber-reinforced HEMA-PU(PBA 700)/St./UP composites containing two different contents of HEMA-PU(PBA 700). The values

Table 4

Bulletproof tests of UHMWPE fiber/HEMA-PU/St./UP composites and Aramid fiber/HEMA-PU/St./UP composites

\begin{tabular}{|c|c|c|c|c|c|}
\hline \multirow[t]{2}{*}{ System (fiber content; vol.\%) } & \multirow{2}{*}{$\begin{array}{l}\text { Standard testing } \\
\text { method }\end{array}$} & \multirow[t]{2}{*}{ Results } & \multirow{2}{*}{$\begin{array}{l}\text { Fiber weight/unit composite } \\
\text { area }\left(\mathrm{g} / \mathrm{cm}^{2}\right)\end{array}$} & \multicolumn{2}{|c|}{ Result photographs } \\
\hline & & & & Front face & Rear face \\
\hline $\begin{array}{l}3 \mathrm{~mm} \text { UHMWPE fiber composite } \\
(30.93 \text { vol. } \%)\end{array}$ & $\begin{array}{l}\text { NIJ 0108.01 II A } \\
(380 \mathrm{~m} / \mathrm{s})\end{array}$ & Penetrated & 0.09 & & \\
\hline
\end{tabular}

$3 \mathrm{~mm}$ Aramid fiber composite (31.18 vol. $\%)$

$5 \mathrm{~mm}$ UHMWPE fiber composite (26.80 vol. \%)

$5 \mathrm{~mm}$ Aramid fiber composite (27.34 vol. \%)

$10 \mathrm{~mm}$ UHMWPE fiber composite (28.87 vol.\%)

$10 \mathrm{~mm}$ Aramid fiber composite (28.78 vol.\%)
NIJ 0108.01 II A Penetrated $(380 \mathrm{~m} / \mathrm{s})$

NIJ 0108.01 II A Penetrated

0.13 $(380 \mathrm{~m} / \mathrm{s})$

NIJ 0108.01 II A Penetrated

0.19 $(380 \mathrm{~m} / \mathrm{s})$

NIJ 0108.01 III A

Not $(433 \mathrm{~m} / \mathrm{s})$

penetrated

NIJ 0108.01 III A

Not $(433 \mathrm{~m} / \mathrm{s})$

penetrated

0.28

0.40
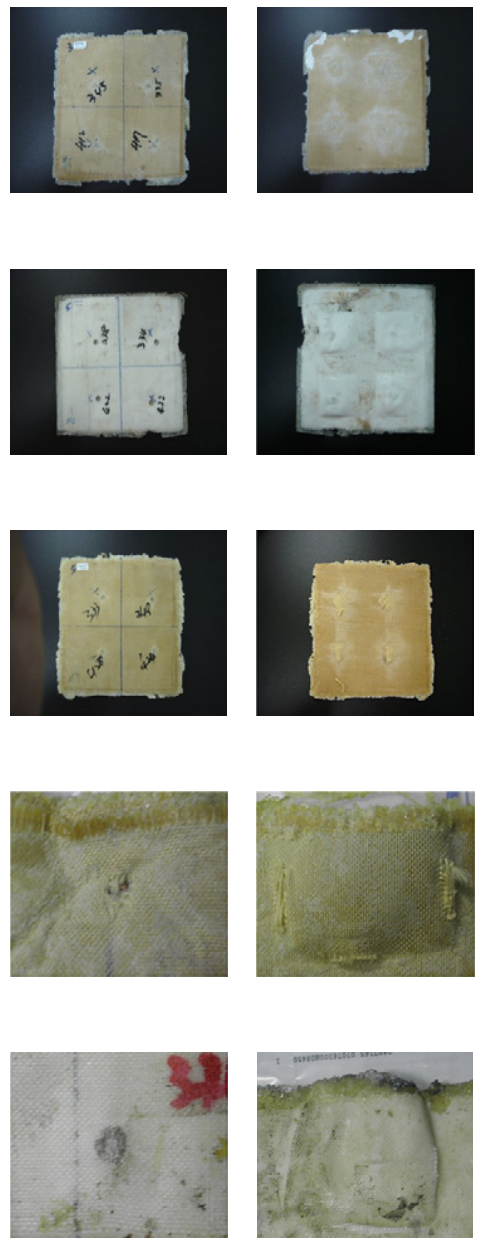
of tensile strength and elongation of the UHMWPE fiberand aramid fiber-reinforced HEMA-PU(PBA 700)/St./UP composites incorporating HEMA-PU content of 8 and $20 \mathrm{wt} \%$ were clearly higher than those of the two corresponding glass fiber-reinforced composites. These findings suggest that the UHMWPE and aramid fibers have potential for application as next-generation fiber-reinforcement materials.

\subsection{Bulletproof properties}

Because the HEMA-PU(PBA 700)/St./UP (20/20/60 in weight ratio) system exhibited the lowest volume shrinkage and highest Izod impact energy, we manufactured UHMWPE fiber knit- and aramid fiber knit-reinforced HEMA-PU(PBA 700)/St./UP (20/20/60, weight ratio) composites and subjected them to tests of their bulletproof nature. Table 4 lists the results of bulletproof testing of these two kinds of fiber knit-reinforced HEMAPU(PBA 700)/St./UP (20/20/60, weight ratio) composites. From standard testing using the NIJ 0108.01 IIA method at thickness of 3 and $5 \mathrm{~mm}$, neither the UHMWPE fiber knit/HEMA-PU/St./UP composite nor the aramid fiber knit/HEMA-PU/St./UP composite was bulletproof (i.e., they were penetrated). In contrast, from standard tests using the NIJ 0108.01 IIIA method at a thickness of $10 \mathrm{~mm}$, both the UHMWPE fiber knit/HEMA-PU/St./ UP and aramid fiber knit/HEMA-PU/St./UP composites were bulletproof (i.e., they were not penetrated). The fiber weight per unit composite area played an important role in affecting the bulletproof nature. For example; using the NIJ 0108.01 IIIA method at a thickness of $10 \mathrm{~mm}$, the fiber weight per unit composite area of $10 \mathrm{~mm}$ thickness composites were greater than other two smaller thickness ( 3 and $5 \mathrm{~mm}$ ), and they could passed the bullet-proof testing via produced the deformation and delimination of composites to adsorb the high-speed impact energy.

\section{Conclusion}

The optimal addition of styrene to the St./UP system to provide the strongest material was $40 \mathrm{wt} \%$, albeit with a high volume shrinkage. After the addition of two kinds of HEMA-PU as volume shrinkage modifiers for the St./ UP system, we found that a lower HEMA-PU content $(8 \mathrm{wt} \%)$ led to a higher tensile strength, whereas a higher HEMA-PU content $(20 \mathrm{wt} \%)$ increased the Izod impact energy and decreased the degree of volume shrinkage in both types of polyol-modified HEMA-PU/St./UP systems. The HEMA-PU(PBA 700)/St./UP system exhibited higher values of tensile and Izod impact energies relative to those of the HEMA-PU(PPG 400)/St./UP system at both 8 and $20 \mathrm{wt} \%$ HEMA-PU addition.

The UHMWPE fiber- and aramid fiber-reinforced HEMA-PU(PBA 700)/St./UP composites displayed clearly higher values of tensile strength and elongation than did the two corresponding types of glass fiber-reinforced composites. Thus, it seems that the UHMWPE and aramid fibers have the potential for application as next-generation fibers reinforcement materials. The mechanical properties of the UHMWPE fiber- and aramid fiber-reinforced composites were different, suggesting that these two kinds of fibers were suited to applications in different fields.

\section{References}

[1] Lee DS, Han CD. Effect of the chemical structure of low-profile additives on the curing behavior and chemorheology of unsaturated polyester resin. Poly Eng Sci 1987;27(13):964-75.

[2] Lam PWK. A comparative study of structure-property relationships in low-profile polyester matrices. Poly Eng Sci 1989;29(10): 690-8.

[3] Yang YS, Suspene L. Curing unsaturated polyester resins: viscosity studies and simulations in pre-gel state. Poly Eng Sci 1991;31(5): $321-32$.

[4] Cao X, Lee LJ. Control of shrinkage and residual styrene of unsaturated polyester resins cured at low temperatures: I. effect of curing agents. Polymer 2003;44(6):1893-902.

[5] Cao X, Lee LJ. Control volume shrinkage and residual styrene of unsaturated polyester resins cured at low temperatures: II. Effect of comonomer. Polymer 2003;44(5):1507-16.

[6] Li W, Lee LJ. Shrinkage control of low-profile unsaturated polyester resins cured at low temperature. Polymer 1998;39(23):5677-87.

[7] Li W, Lee LJ. Low temperature cure of unsaturated polyester resins with thermoplastic additives I. dilatometry and morphology study. Polymer 2000;41(2):685-96.

[8] Li W, Lee LJ. Low temperature cure of unsaturated polyester resins with thermoplastic additives II. Structure formation and shrinkage control mechanism. Polymer 2000;41(2):697-710.

[9] Li W, Lee LJ. Low temperature cure of unsaturated polyester resins with thermoplastic additives III. Modification of polyvinyl acetate for better shrinkage control. Polymer 2000;41(2):711-7.

[10] Huang YJ, Su CC. Effects of poly(vinyl acetate) and poly(methyl methacrylate) low-profile additives on the curing of unsaturated polyester resins II. Morphological changes during cure. J Appl Polym Sci 1995;55(2):323-42.

[11] Huang YJ, Liang CM. Volume shrinkage characteristics in the cure of low-shrink unsaturated polyester resins. Polymer 1996;37(3): 401-12.

[12] Huang YJ, Horng JC. Effects of thermoplastic additives on mechanical properties and glass transition temperatures for styrene-crosslinked low-shrink polyester matrices. Polymer 1998;39(16):3683-95.

[13] Zhang Z, Zhu S. Microvoids in unsaturated polyester resins containing poly(vinyl acetate) and composites with calcium carbonate and glass fibers. Polymer 2000;41(10):3861-70.

[14] Lin JM, Ma CCM, Tai NH, Chang WC, Tsai CC. Carbon fiber reinforced phenolic resin/silica ceramer composites-processing, mechanical and thermal properties. Polym Compos 2000;21(2):305-11.

[15] Hung AY, Wang FY, Yeh SR, Chen WJ, Ma CCM. Carbon/ carbon composites derived from poly(ethylene oxide)-modified novolac-type phenolic resin: microstructure and physical, and morphological properties. J Appl Polym Sci 2002;84(8):1609-19.

[16] Wu HD, Ma CCM, Lin JM. Processability and properties of phenoxy resin toughened phenolic resin composites. J Appl Polym Sci 1997;63(7):911-7.

[17] Ma CCM, Lee CT, Wu HD. Mechanical properties, thermal stability, and flame retardance of pultruded fiber-reinforced poly(ethylene 
oxide)-toughened novolak-type phenolic resin. J Appl Polym Sci 1998;69(6):1129-36

[18] Ma CCM, Tseng HT, Wu HD. Blocked diisocyanate polyestertoughened novolak-type phenolic resin:synthesis, characterization, and properties of composites. J Appl Polym Sci 1998;69(6): 1119-27.

[19] Wang FY, Ma CCM, Wu WJ. Mechanical properties, morphology, and flame retardance of glass fiber-reinforced polyamide-toughened novolac-type phenolic resin. J Appl Polym Sci 1999;73(6):881-7.

[20] Arnold JJ, Zamora MP, Brennan AB. Characterization of UHMWPE fiber/matrix adhesion by dynamic mechanical spectrometry. Polym Compos 1996;17(3):332-42.
[21] Pegoretti A, Ashkar M, Migliaresi C, Marom G. Relaxation processes in polyethylene fiber-reinforced polyethylene composites. Compos Sci Technol 2000;60(8):1181-9.

[22] Cherian AB, Thachil ET. Block copolymers of unsaturated polyesters and functional elastomers. J Appl Polym Sci 2004;94(5):1956-64.

[23] Lin SP, Han JL, Yeh JT, Chang FC, Hsieh KH. Surface modification and physical properties of various UHMWPE-fiber-reinforced modified epoxy composites. J Appl Polym Sci 2006;104(1):655-65.

[24] Lin SP, Han JL, Yeh JT, Chang FC, Hsieh KH. Composites of UHMWPE fiber reinforced PU/epoxy grafted interpenetrating polymer networks. Eur Polym J 2007;43(3):996-1008. 